www.jmscr.igmpublication.org

Impact Factor 5.84

Index Copernicus Value: 83.27

ISSN (e)-2347-176x ISSN (p) 2455-0450

crossref DOI: https://dx.doi.org/10.18535/jmscr/v5i7.164

Journal Of Medical Science And Clinical Research

IGM Publication

An Official Publication of IGM Publication

\title{
A Clinical Study of 350 Oligohydromnios Cases in a Tertiary Care Centre
}

\author{
Authors \\ Suman Meena ${ }^{1}$, Ram Gopal Meena ${ }^{2}$, Anjali Jasawat ${ }^{3}$, Mamta Sabal $^{4}$ \\ ${ }^{1}$ Assistant Professor, Dept of Obstretic and Gynecology, GMC, Kota \\ ${ }^{2}$ Assistant Professor, Dept of Surgery, GMC, Kota \\ ${ }^{3,4}$ Post Graduate, Dept of Obstretic and Gynecology, GMC, Kota \\ Corresponding Author \\ Ram Gopal Meena \\ Email: ramgopalmeena16@gmail.com,Telephone:09462655110
}

\begin{abstract}
oligohydromnnios is defined as reduction in amniotic fluid volume or AFI $<5 \mathrm{~cm}$. For maternal and fetal health oligohydromnios has become a threatening condition. With the aim of highlighting the condition of oligohydromnios in our institute. This retrospective study including 350 term pregnancy cases were taken who had undergone caesarian section with the indication of oligohydromnios. Maternal condition like the hypertension, premature rupture of membranes, postdated pregnancies, age and parity were seen and fetal condition in term of the fetal weight, presence of the meconium stained liquor and status of the baby at term whether alive or dead were noted. In results we found $95 \%$ of patients were in the age group of 20-30 years and $62 \%$ of them were primigravida. $74 \%$ of cases were idiopathic where no cause could be found followed by the postdated pregnancies (11.7\%) and Pregnancy induced hypertension (). Fetal distress was present in $39.4 \%$, meconium stained liquor was seen in $28 \%$ of cases. $75 \%$ of the babies were of the average weight, while only $24 \%$ were underweight. All of these babies were alive at birth. With this study will concluded that adverse fetal outcome is associated with oligohydromnios.
\end{abstract}

Keywords: oligohydromnios, meconium, primigravida.

\section{INTRODUCTION}

Oligohydramnios is defined as amniotic fluid index less than $5 \mathrm{~cm}$ or maximum vertical pocket devoid of cord is less than $2 \mathrm{~cm}$. The incidences of oligohydramnios are influenced by variation in diagnostic criteria, period of gestation studied and the threshold used at that time of gestation. Naturally the amniotic fluid volume decrease in third trimester, oligohydramnios is more common at term. One study including 3050 uncomplicated pregnancies between 40 \& 41 weeks gestation, rate of oligohydramnios was found out to be
$11 \%{ }^{(1)}$. Amniotic fluid provides an ideal environment for fetal development \& growth. It provides the fetus with water, participates in fetal metabolism, maintains a constant temperature \& plays a crucial role in the development of fetal lungs. It protects the fetus from infection through its bacteriostatic properties \& prevents the compression of umblical cord. Amniotic fluid volume changes dramatically during the pregnancy along with changes in its content. This volume peaks at around 34 weeks and subsequently decreases during the pregnancy. 
Amniotic fluid volume can be measured ultrasonographically which is a reliable method of its estimation, either as total amniotic fluid index $<5 \mathrm{cms}$ or by seeing the deepest vertical pocket less than $2 \mathrm{~cm}$. $^{(2)}$

From various studies done in the past, a number of factors have been found to be associated with oligohyrdamnios. The common conditions associated with oligohydramnios are ruptured membranes, postmaturity, hypertension in pregnancy and fetal anomalies. It can also be an idiopathic finding in a low risk pregnancy having no fetal or medical complication yet predispose to umblical cord occlusion \& the risk of fetal hypoxemia. However, over the last decade some authors have found that diminished volume of amniotic fluid alone is not associated with intrapartum complications. Hence, this study is undertaken to highlight such factors \& their role in affecting fetal outcome in cases of oligohydramnios.

\section{MATERIAL AND METHOD}

This is a retrospective study including a total of 350 patients who were taken for ceasarian section in a period of 1 year in Jk Lon Hospital Kota from january 2016 to december 2016 with indication of oligohydramnios.

A total of 350 cases were taken with sonographically diagnosed oligohydramnios where all cases of oligohydramnios (AFI $<5 \mathrm{cms}$ ) and borderline oligohydramnios (AFI $5-8 \mathrm{~cm}$ )s were taken who had undergone ceasarian section. Cases with oligohydramnios of gestation age less than 37 weeks and with intrauterine deaths were excluded. Analysis was done in these cases with respect to maternal age, parity, gestational age, presence of hypertension and malpresentations. Fetal factors including fetal weight, malformations and Intraoperative findings like meconium stained liquor and fetal distress were taken into account. Fetal birth weight and condition at birth were also noted.

\section{RESULTS}

Out of total 350 patients, 331 (94\%) patients were in the age group of 20 -30 yrs followed by more than 30 yrs group and only 4 patients were less than 20 yrs.

\begin{tabular}{|l|c|c|}
\hline Age $(\mathrm{yrs})$ & No. of patients & $\%$ \\
\hline Less than 20 yrs & 04 & $1 \%$ \\
\hline $20-30$ & 331 & $94 \%$ \\
\hline$>30$ & 15 & $4.2 \%$ \\
\hline & & \\
\hline
\end{tabular}

The incidence of oligohydramnios was highest in primigravidas 218(62.2\%) followed by multigravidas $117(33 \%)$ and only $15(4.2 \%)$ cases were seen in four or higher gravidas.

\begin{tabular}{|l|c|c|}
\hline Parity & Number of patients & Percentage \\
\hline G1 & 218 & $62.2 \%$ \\
\hline >or equal toG2 & 117 & $33 \%$ \\
\hline >or equal to G4 & 15 & $4.2 \%$ \\
\hline
\end{tabular}

The most common risk factor associated with oligohydramnios was idiopathic seen in 260(74\%) cases followed by postdated pregnancy in $41(11.7 \%)$, pregnancy induced hypertension in 34 (9.7\%) and rupture of membranes was seen in only 20 cases $(5.7 \%)$.Fetal anomalies were present in 5 cases $(1.4 \%)$.

\begin{tabular}{|l|c|c|}
\hline Risk Factors & No. of patients & $\%$ \\
\hline Idiopathic & 260 & $74 \%$ \\
\hline Hypertension in pregnancy & 34 & $9.7 \%$ \\
\hline Postdated pregnancy & 41 & $11.7 \%$ \\
\hline Rupture of membranes & 20 & $5.7 \%$ \\
\hline Fetal anomalies & 3 & $0.8 \%$ \\
\hline
\end{tabular}

In Fetal Outcome, Birth weight were analysed and it was found that $85(24.2 \%)$ babies were underweight; $<2.5 \mathrm{~kg}$ and $2(0.5 \%)$ babies were below $1.5 \mathrm{~kg}$ weight while $263(75 \%)$ babies had average birth weight of $2.5 \mathrm{kgs}$.

\begin{tabular}{|l|l|l|}
\hline Birth weight & No. of babies & $\%$ \\
\hline$>$ or equal to $2.5 \mathrm{~kg}$ & 263 & $75 \%$ \\
\hline$<2.5 \mathrm{~kg}$ & 85 & $24.2 \%$ \\
\hline$<1.5 \mathrm{~kg}$ & 2 & $0.5 \%$ \\
\hline
\end{tabular}

Meconium stained liquor was found in 98(28\%)cases and malpresentation were seen in 26(7.4\%) cases. Fetal distress was present in 138 (39.4\%) cases. 


\section{DISCUSSION}

Most of the patients in our study were found in the age group of 20-30yrs (94.5\%) followed by more than $30 y r s$ age group.Bengal et al ${ }^{(3)}$ found the mean maternal age for patients with oligohydramnios was 22.8 yrs and the results were also similar in another study by Guin et $\mathrm{al}^{(4)}$ where the mean age was 24 yrs. Our study also had similar results of the mean age of $21 \mathrm{yrs}$.

Oligohydramnios was seen affecting primigravidas the most i.e $218(62 \%)$ which is similar to that found by Donald et al where it was $60 \% .^{(5)}$

Most common cause of oligohydramnios was found to be idiopathic (74\%). Second most common cause was postdated pregnancy 41 $(11.7 \%)$ followed by pregnancy induced hypertension $34(9.7 \%)$ and lastly rupture of membranes in 20 cases(5.7\%). Fetal anomalies were associated with oligohydramnios in only 5 cases $(0.8 \%)$ in our study.

These results were similar to that found by K.jakatia in $2013^{(6)}$ where most common cause was idiopathic in $52 \%$ patients followed by pregnancy induced hypertension $25 \%$.

Another study by Vibha Moses in 2016(7), idiopathic cause was found in most of the cases (32\%) followed by pregnancy induced hypertension in $26 \%$ cases and post dated pregnancy in $23 \%$ cases while only $9 \%$ cases of pre mature rupture of membranes were seen.

In the present study, $85(24.2 \%)$ babies had birth weight less than $2.5 \mathrm{~kg} \& 2(0.5 \%)$ had birth weight less than $1.5 \mathrm{~kg}$. A study by Sowmya $\mathrm{K}$ et al ${ }^{8)} 48 \%$ babies were underweight out of 50 patients in AFI $<5 \mathrm{cms}$ group .The difference in results between two studies can be explained due to more patients \& that too with the inclusion of both oligohydramnios \& borderline oligohydramnios in our study.

Meconium stained liquor was found in 98 cases (28\%) and fetal anomalies were seen in 19 cases (\%). In 26 cases, malpresentations were associated with oligohydramnios. A study by Preshit et al in 2012, he found occurrence of meconium stained liquor in women with AFI $<5 \mathrm{cms}$ was $48 \%{ }^{(9)}$. The less number of cases with meconium in our study is also because of the fact that all cases here are not having amniotic fluid index $<5 \mathrm{~cm}$. Fetal distress was present in 138 cases (39.4\%). which is quite similar to a study by Syria et al who that found fetal distress was present in $48 \%$ cases. ${ }^{(10)}$

\section{CONCLUSION}

Oligohydramnios $(<5 \mathrm{~cm})$ and Borderline oligohydramnios $(5-8 \mathrm{~cm})$ are associated with adverse fetal outcome. Various factors can be responsible for oligohydramnios, out of which postdated pregnancies, pregnancy induced hypertension and premature rupture of membranes are most common. Fetal anomalies are a rare cause and So with this knowledge these factors if detected earlier in antenatal checkups, oligohydramnios incidences can reduced to some extent, such factor and their adverse effects on fetal weight and risk of meconium aspiration syndrome can be reduced.

\section{BIBLIOGRAPHY}

1. Locatelli A, ZoKarella A,Toso $S$ et al.Serial Assessment of amniotic fluid index in uncomplemented term pregnancies; Prognostic value of amniotic fluid reduction.J Maternal fetal neonatal Med 2004;15(233)

2. Magann EF,Chauhan SP,Bofill JA,Martin JN.Comparability of AFI and single deepest pocket measurement in clinical practice. Aust NZ J Obstetrics Gynaecol. 2003;43:75-77

3. Bengal VB Purshottam AG,Bhushan MS.Incidence of oligohydramnios dyring pregnancy and its effects on maternal and perinatal outcome.J Pharma Biomed Sci 2011;12(12):5

4. Guin G,Punekar S,Lele A,Khare S.A prospective study of fetomaternal outcome in pregnancy of abnormal liquor volume. Jr. Obstet Gynaecol India:2011:61:652-5

5. Casey BM.McIntine DD,Bloom SL,Lucal MS,Santes R, Twickler DM et 
al.Pregnancy outcomes after anteparum diagnosis of oligohydramnios at or beyond 34 weeks of gestation.Am.Jr.Obet Gynaecol 2000;182(4):909-12

6. Krishna Jakatia,Nisha Singh,Sachin Patel. Maternal \& Fetal outcome in oligohydramnios : A study of 100 cases Int.J. Med.Sci. Public Health 2013;2(3):724-727

7. Vibha Moses,Sarita Thakre.A study of maternal \& Fetal outcome in third trimester diagnosed case of oligohydramnios. Int.Jr. of Reproduction ,Contraception Obsteric Gynaecol2016 sept;5(9):29442948

8. Sawmya K, Betty Varghese and Umashankar Borkar Y et al.Effect of isolated oligohydramnios in the otherwise normal term pregnancy.Int.Jr. of Biomedical Research (2014)5(2)

9. Preshit Chate,Meena Khatri \& C Hariharan et al.Pregnancy outcome after diagnosis of oligohydramnios at term.Int.Jr.of Reproduction, Contraception,Obsteric \& Gynaecol 2013March 2(1);23-26

10. Syria R,Singhai S,et al.Perinatal outcome in patients with Amniotic fluid index $<5 \mathrm{~cm}$.Jr.Obstet \& Gynae India 2005;51:98-100. 